\title{
Integrated proteomics and metabolomics for dissecting the mechanism of global responses to salt and alkali stress in Suaeda corniculata
}

\author{
Qiuying Pang • Aiqin Zhang • Wei Zang • \\ Lei Wei $\cdot$ Xiufeng Yan
}

Received: 29 October 2015 / Accepted: 8 December 2015 /Published online: 25 January 2016

(C) Springer International Publishing Switzerland 2016

\begin{abstract}
Background and aims Soil alkalinity and salinity are two of the most common environmental stress factors that impact plant growth and productivity. S. corniculata is native to the saline-alkali soil of Northeast China which shows a higher alkali tolerance than other suaeda plants. It will be very important to identify the effect of salt and alkali stress on $S$. corniculata through proteomics and metabolomics analysis to improve understanding of the resistance of plants.

Methods S. corniculata seedlings were exposed to salt and alkali stress for $72 \mathrm{~h}$, respectively. Metabolic changes were quantified by conducting MS-based proteomics and NMR-based metabolomics analysis.
\end{abstract}

Q. Pang and A. Zhang contributed equally to this work.

Responsible Editor: Frans J.M Maathuis.

Electronic supplementary material The online version of this article (doi:10.1007/s11104-015-2774-0) contains supplementary material, which is available to authorized users.

Q. Pang $\cdot$ A. Zhang $\cdot$ W. Zang $\cdot$ X. Yan $(\bowtie)$

Alkali Soil Natural Environmental Science Center, Northeast Forestry University/Key Laboratory of Saline-alkali Vegetation Ecology Restoration in Oil Field, Ministry of Education, Harbin 150040, People's Republic of China

e-mail: xfyan@nefu.edu.cn

\section{Wei}

Key Laboratory of Coastal Zone Environmental Processes, Yantai Institute of Coastal Zone Research (YIC), Chinese Academy of Sciences (CAS), Shandong Provincial Key Laboratory of Coastal Zone Environmental Processes, YICCAS, Yantai 264003, People's Republic of China
Results The response of $S$. corniculata to salt stress was distinct from that of plants subjected to alkali stress at both physiological and molecular levels. The integrated-omic studies identified 22 and 19 differentially expressed proteins and metabolites mainly involved in carbohydrate metabolism and amino acid metabolism.

Conclusions On account of the up-regulation of energy metabolism and higher accumulation of organic osmolytes, S. corniculata shows high $\mathrm{pH}$ resistance when it suffers alkali stress. These findings provide insights into the different regulatory mechanisms in halophyte $S$. corniculata response to salt and alkali stresses.

Keywords Salinity · Alkalinity · Suaeda corniculata . Proteomics $\cdot$ Metabolomics

$\begin{array}{ll}\begin{array}{l}\text { Abbreviations } \\ \text { 2-DE }\end{array} \text { MALDI-TOF/TOF } & \begin{array}{l}\text { Two dimensional electrophoresis } \\ \text { Matrix-assisted laser desorption/ } \\ \text { ionization time-of-flight/time-of- } \\ \text { flight } \\ \text { Iodoacetamide } \\ \text { Ribulose bisphosphate carbox- } \\ \text { ylase/oxygenase }\end{array} \\ \text { RuBisCO } & \begin{array}{l}\text { Glyceraldehyde 3-phosphate } \\ \text { dehydrogenase }\end{array} \\ \text { GAPDH } & \begin{array}{l}\text { Tricarboxylic acid } \\ \text { Dithiothreitol }\end{array} \\ \text { TCA } & \text { Acetonitrile } \\ \text { DTT } & \text { Trifluoroacetic acid } \\ \text { ACN } & \end{array}$




\section{Introduction}

Soil salinization is one of the most common abiotic stressors to plant growth and productivity (Zhu 2001). Saline and sodic soils cover approximately $10 \%$ of total arable lands and exist in over 100 countries (Wallender and Tanji 1990). For example, in the northeast of China, alkalinized grassland has exceeded $70 \%$ (Kawanabe and Zhu 1991). Compared to salt stress, alkali stress adds the influence of high $\mathrm{pH}$, which can inhibit uptake and disrupt the ionic balance of plant cells (Yang et al. 2007). With the increasing levels of soil salinization and alkalization worldwide, improving the salinity and alkali tolerance of plants is an important global priority, and in the near future it will be very important to identify strategies for improving the resistance of plants to salt and alkali stresses, so as to enable increasing the tolerance of crops to salt stress through the use of genetic engineering technologies.

Suaeda species are annual euhalophytes, among the most common plants in saline and alkaline soils, which are important halophyte resources with highly succulent leaves and able to accommodate ions without the need for secretion via salt glands and are widely distributed throughout the world (Shao and Li 1998; Flowers and Colmer 2008). More than twenty species of Suaeda have been reported for their ability to survive high salt conditions, including $S$. salsa (Zhang and Zhao 1998), S. maritima (Maathuis et al. 1992; Wetson and Flowers 2010), S. aegyptiaca (Askari et al. 2006), S. asparagoides (Ayarpadikannan et al. 2012), S. fruticosa (Khan and Ungar 1998), S. glauca (Yang et al. 2008b, S. physophora (Song et al. 2006) and S. corniculata (Wei et al. 2012). In particular, recent studies of salt responsive physiology, molecular genetics, proteomics and metabolomics in S. salsa have yielded more information for understanding the complex mechanisms of Suaeda plants' salt response and tolerance (Zhang et al. 2001; Lu et al. 2003; Pang et al. 2005; Han et al. 2011; Li et al. 2011, 2011b; Wu et al. 2012). In previous studies of $S$. salsa, salt treatment caused the up-regulation of aquaporin (Qi et al. 2009), vacuolar $\mathrm{Na}^{+} / \mathrm{H}^{+}$antiporter (Qiu et al. 2007), V-ATPase and V-PPase (Wang et al. 2001), indicating that Suaeda can maintain homeostasis in water potential and ion distribution by increasing leaf succulence and compartmenting the ions. The choline monooxygenase (CMO) and betaine aldehyde dehydrogenase (BADH) genes in $S$. salsa which encode the enzymes involved in the synthesis of osmolytes were up-regulated under salt stress, suggesting that Suaeda plants could enhance their resistance to the osmotic stress by the accumulation of osmolytes when subjected to salt stress (Wu et al. 2012). In addition, salt stress accelerates the production of reactive oxygen species (ROS) in plant cells (Zhu 2001), and halophytes such as Suaeda species can maintain the balance between formation and removal of ROS by increasing the activity of antioxidant enzyme such as SOD (Wang et al. 2004; Guan et al. 2011), APX (Pang et al. 2005), GPX (Wu et al. 2012), and CAT (Pang et al. 2005; Wu et al. 2012).

As a member of the Suaeda genus, S. corniculata is native to the saline-alkali soil of Northeast China (Guan et al. 2010). S. corniculata shows a higher alkali tolerance than $S$. salsa and can survive in saline-sodic soil with $\mathrm{pH}$ ranged from 10 to 15.5 ( $\mathrm{Lu}$ and $\mathrm{Li}$ 1994; Liu et al. 2011a). In this study, an integrated comparative proteomic and metabolomic approach was conducted identify the differentially expressed proteins and metabolites in $S$. corniculata under salt and alkali stresses, coupled with the analysis of protein function and metabolic pathways. This study is of prime interest to understand the underlying molecular mechanism of salt and alkali tolerance in S. corniculata and expand our knowledge of the metabolic processes by which Suaeda plants adapt to saline and alkaline soils.

\section{Materials and methods}

Plant material, growth conditions, stress treatment

Seeds of $S$. corniculata were collected from a salinealkali soil area located in Zhaodong, Heilongjiang province, Northeast China. The seeds were soaked in distilled water for $2 \mathrm{~h}$ and sown in polyvinylchloride (PVC) cylinders filled with distilled water washed sand. Seedlings were grown in a greenhouse at $25 / 20{ }^{\circ} \mathrm{C}$ (day/night) with a $8 \mathrm{~h}$ light/16 h dark photoperiod, photosynthetically active radiation $150 \mu \mathrm{mol} \cdot \mathrm{m}^{-2} \cdot \mathrm{s}^{-1}$ and $50-70 \%$ relative humidity and were irrigated daily by half strength Hoagland's solution $(\mathrm{pH} 6.21 \pm 0.10)$. Four-week-old seedlings were transferred to hydroponic culture containers in half strength Hoagland's solution, which were changed daily, 12 plants were placed in each container filled with $1000 \mathrm{~mL}$ solution. After a week, the seedlings were treated with half strength Hoagland's solution containing 0, 100,150, 
200, $300 \mathrm{mM} \mathrm{NaCl}(\mathrm{pH} 6.12 \pm 0.08)$ and 0, 50, 100, $150,200 \mathrm{mM} \mathrm{NaHCO}_{3}(\mathrm{pH} 8.37 \pm 0.15)$, the concentrations setting refer to previous studies on S.salsa, $S$. maritime and S. glauca (Flowers et al. 1976; Yang et al. 2008; Song et al. 2009). Five independent biological replicates were used in physiological analysis. After exposure for $72 \mathrm{~h}$, the aboveground part of seedlings from control and exposed groups were randomly harvested and used for experiment, separately.

\section{Measurement of biomass}

Plants were harvested after exposure for $72 \mathrm{~h}$ and washed with distilled water, followed by surface drying with filter paper. After the determination of Fresh weights (FW), the samples were drying for $10 \mathrm{~min}$ in $105{ }^{\circ} \mathrm{C}$ and dried in an oven at $80{ }^{\circ} \mathrm{C}$ to a constant weight, and then dry weights (DW) was determined. Five plants of each treatment were independently carried out as biological replicates. One-way ANOVA was used to test the differences between control and each treatment followed by Tukey post hoc test. The differences were considered significant when $p<0.05$.

$\mathrm{Na}^{+}, \mathrm{K}^{+}$content analysis

Plants were harvested after exposure for $72 \mathrm{~h}$ and washed with distilled water, followed by surface drying with filter paper. The samples were oven-dried in an oven at $80^{\circ} \mathrm{C}$ to a constant weight. Dry samples were homogenized by powdering and $20 \mathrm{mg}$ of dry samples were treated with $1 \mathrm{ml} 10 \%$ nitric acid for $24 \mathrm{~h}$. The extract was used to determine the contents of $\mathrm{Na}^{+}$and $\mathrm{K}^{+}$with flame atomic absorption spectrometer (AAS) (TAS-986, Beijing, China). Three replicates were used for each treatment. One-way ANOVA was used to test the differences between control and each treatment followed by Tukey post hoc test. The differences were considered significant when $p<0.05$.

Proteomics analysis

\section{Protein extraction}

The proteins were extracted by the acetone/ trichloroacetic acid method. Approximately $1 \mathrm{~g}$ fresh leaf tissue were harvested after exposure for $72 \mathrm{~h}$ from each treatment and ground into fine powder in liquid nitrogen. Three replicates were used for each treatment. The powder was precipitated in a $10 \%$ $(w / v)$ TCA, acetone solution containing $0.07 \%(v / v) \beta$ mercaptoethanol at $-20{ }^{\circ} \mathrm{C}$ overnight. The mixture was centrifuged at $40,000 \mathrm{~g}$ at $4{ }^{\circ} \mathrm{C}$ for $1 \mathrm{~h}$ and the precipitates were washed with cold acetone containing $0.07 \%$ $(v / v) \beta$-mercaptoethanol for three times. Pellets were dried by vacuum centrifuge and dissolved in $7 \mathrm{M}$ urea, 2 M thiourea, $4 \%(w / v)$ cholamidopropyl CHAPS, $40 \mathrm{mM}$ dithiothreitol (DTT), $2 \%(v / v)$ pharmalyte 4-7 (GE Healthcare, Waukesha, WI, USA), and $1 \%(v / v)$ proteinase inhibitor (GE Healthcare, Waukesha, WI, USA) and shaked vigorously for $2 \mathrm{~h}$ at room temperature before being centrifuged at 40,000 $\mathrm{g}$ at $4{ }^{\circ} \mathrm{C}$ for $1 \mathrm{~h}$. The subsequent supernatant was collected. The protein concentration was determined using the 2D Quant kit (GE Healthcare, Waukesha, WI, USA) with BSA as a standard. Sample were frozen in liquid nitrogen and kept at $-80^{\circ} \mathrm{Cuntil}$ further use.

\section{Two dimensional gel electrophoresis}

Two dimensional electrophoresis of protein extracts was performed using a GE Healthcare 2-DE system according to the manufacturer's manuals. Each $1300 \mu \mathrm{g}$ protein sample was loaded by rehydration to immobiline Dry Strips ( $\mathrm{pH}$ 4-7 linear, $24 \mathrm{~cm}$ ) (GE Healthcare, Waukesha, WI, USA). The separation on an IPGphor II unit (GE Healthcare, Waukesha, WI, USA) was performed with the following parameters: $30 \mathrm{~V}$ for $8 \mathrm{~h}$, $50 \mathrm{~V}$ for $4 \mathrm{~h}, 100 \mathrm{~V}$ for $1 \mathrm{~h}, 300 \mathrm{~V}$ for $1 \mathrm{~h}, 500 \mathrm{~V}$ for $1 \mathrm{~h}$, $1000 \mathrm{~V}$ for $1 \mathrm{~h}$, and $8000 \mathrm{~V}$ for $12 \mathrm{~h}$ using hydration buffer ( $8 \mathrm{M}$ urea, $2 \%$ CHAPS, $20 \mathrm{mM}$ DTT) containing $0.6 \%(v / v)$ IPG buffer. After isoelectric focusing, the strips were equilibrated with $10 \mathrm{ml}$ equilibration buffer I containing $6 \mathrm{M}$ urea, $2 \% \mathrm{SDS}, 2.5 \mathrm{mM}$ Tris- $\mathrm{HCl}$ (pH 8.8), $30 \%$ glycerol, and $1 \%$ DTT for $15 \mathrm{~min}$, followed with $10 \mathrm{ml}$ equilibration buffer II containing $6 \mathrm{M}$ urea, $2 \% \mathrm{SDS}, 2.5 \mathrm{mM}$ Tris-HCl (pH 8.8), $30 \%$ glycerol, and $4 \%$ 2-iodoacetamide (IAA) for $15 \mathrm{~min}$. The second dimension separation of proteins was performed on SDS-PAGE gel (12.5\% polyacrylamide) using Ettan ${ }^{\mathrm{TM}}$ Daltsix apparatus (GE Healthcare, Waukesha, WI, USA). The electrophoresis was carried out at $25{ }^{\circ} \mathrm{C}$ and $3.5 \mathrm{w} /$ gel for $30 \mathrm{~min}$ and then $17.5 \mathrm{w} /$ gel for $4.5 \mathrm{~h}$ until the bromophenol blue dye front arrived at the bottom of the gels. 
Image and statistical analysis

Proteins were visualized by coomassie brilliant blue R250 staining, and gel images were acquired using an ImageScanner (GE Healthcare, Waukesha, WI, USA). Image analysis was performed with ImageMaster 2D Platinum Software Version 7.0 (GE Healthcare, Waukesha, WI, USA). After automated detection and matching, manual editing was carried out to correct the mismatched and unmatched spots. Spots were considered reproducible when they were well resolved in the three biological replicates. For each matched spot, a measurement was carried out for each biological replicate, and normalized volumes were computed using the total spot volume normalization procedure of the software. The normalized volume of each spot was assumed to represent its expression abundance. A criterion of $p<0.05$ and an abundance ratio of at least 2.0 were used to define significant differences when analyzing parallel spots between groups with two-way ANOVA.

\section{In-gel digestion and MALDI-TOF/TOF analysis}

Selected spots were excised from 2D gels, washed with sterile deionized water, and digested with trypsin as described previously (Chen et al. 2011). For MALDITOF/TOF MS analysis, tryptic peptides were desalted with C18 Ziptips (Millipore) and spotted onto a MALDI plate by mixing $1: 1$ with the matrix solution $(1 \%$ acyano-4-hydroxy-trans-cinnamic acid in $60 \% \mathrm{ACN}$ containing $0.1 \%$ TFA). MS/MS spectra were acquired using a 4800 MALDI-TOF/TOF mass spectrometer (Applied Biosystems/MDS Sciex, USA). The peptide MS/MS spectra were searched against NCBI nonredundant fasta database $(8,224,370$ entries, downloaded on April 14, 2009) using MASCOT search engine (http:// www.matrixscience.com). Mascot was set up to search green plants only, assume trypsin digestion and one allowed miscleavage. The mass tolerance for both parent ion and fragment ion mass was set to be $0.3 \mathrm{Da}$. Iodoacetamide derivatization of Cys, deamidation of Asn and Gln, and oxidation of Met were specified as variable modifications. Unambiguous identification was judged by the number of peptides, sequence coverage, MASCOT MOWSE score and the quality of MS/MS spectra.

For the proteins identified by MASCOT, their accession numbers were directly searched against the NCBInr database (http://blast.ncbi.nlm.nih.gov/) to obtain the proteins corresponding blast information. Noncommercial databases, KEGG (http://www.genome.jp/ $\mathrm{kegg} /$ pathway.html), were utilized to search for protein functional classification.

Metabolomics analysis

\section{Metabolite extraction}

Polar metabolites were extracted from the leaves of $S$. corniculata using the solvent system of methanol/water (1/1), as described previously (Wu et al. 2011). Six replicates were used for each treatment. The fresh leaf tissue (approximately $100 \mathrm{mg}$ ) was ground in liquid nitrogen with a mortar and pestle. The tissue powder was transferred to a tube containing approximate 50 ceramic beads with $1 \mathrm{~mm}$ diameter and homogenized in $3.33 \mathrm{ml} \mathrm{g}^{-1}$ methanol/water (1/1). After vortex mixing for $15 \mathrm{~s}$ three times, the homogenate was centrifuged at $3000 \times \mathrm{g}$ for $10 \mathrm{~min}$ at $4{ }^{\circ} \mathrm{C}$, the supernatant was removed and then lyophilized. It was subsequently resuspended in $600 \mu \mathrm{L}$ phosphate buffer $(0.1 \mathrm{M}$ $\mathrm{Na}_{2} \mathrm{HPO}_{4}$ and $\mathrm{NaH}_{2} \mathrm{PO}_{4}$, including $0.5 \mathrm{mM}$ TSP, $\mathrm{pH}$ 7.0) in $\mathrm{D}_{2} \mathrm{O}$. Before being centrifuged at $3000 \mathrm{~g}$ for $5 \mathrm{~min}$ at $4{ }^{\circ} \mathrm{C}$, the mixture was vortexed for $15 \mathrm{~s}$, and then the supernatant substance $(550 \mu \mathrm{L})$ was pipetted into a $5 \mathrm{~mm}$ NMR tube for following NMR analysis.

\section{NMR analysis}

Extraction analysis of $S$. corniculata leaf tissue was performed with a Bruker AV 500 NMR spectrometer at $500.18 \mathrm{MHz}$ (at $298 \mathrm{~K}$ ) (Wu et al. 2012). One dimensional (1D) ${ }^{1} \mathrm{H}$ NMR spectra were obtained with the following parameters: $11.9 \mu$ s pulse, $6009.6 \mathrm{~Hz}$ spectral width, $0.1 \mathrm{~s}$ mixing time, and $3.0 \mathrm{~s}$ relaxation delay with standard 1D NOESY pulse sequence, with 128 transients collected into 16,384 data points. Datasets were zero-filled to 32,768 points, and exponential linebroadenings of $0.3 \mathrm{~Hz}$ were applied prior to Fourier transformation.

\section{Data processing and statistical analysis}

All ${ }^{1} \mathrm{H}$ NMR spectra were phased, baseline-corrected, and calibrated (TSP at $0.0 \mathrm{ppm}$ ) using TopSpin (version 2.1, Bruker). Metabolites were assigned and quantified following the tabulated chemical shifts (Wu et al. 2011, 2013; Ji et al. 2013) and using the software Chenomx 
(Evaluation Version, Chenomx Inc., Canada). We used principal components analysis (PCA) in this work for the separation of control and different salt exposed groups. PCA is an exploratory unsupervised pattern recognition (PR) method that calculates inherent variation within the data sets without use of the class membership. The algorithm of PCA calculates the highest amount of correlated variation along principal component (PC1), with subsequent PCs containing correspondingly smaller amounts of variance. For each model built, the loading vectors for the PCs could be used for the identification of the contributive metabolites (metabolic biomarkers) for the clusters (Xu 2004). Data were statistically analyzed using SPSS 13.0. All of the treatments were replicated six times, means and calculated standard deviation (SD) were reported. For test statistical significance $(p<0.05$ and $p<0.01)$ of separations between the control and treated groups, Tukey HSD-test was performed of different samples.

\section{Result}

Plant growth response to $\mathrm{NaCl}$ and $\mathrm{NaHCO}_{3}$ stress

At low concentrations $\mathrm{NaCl}$ and $\mathrm{NaHCO}_{3}$ treatment, $S$. corniculata was fresh and green, but it showed severe wilting and tended to be unwell at $300 \mathrm{mM} \mathrm{NaCl}$ and $200 \mathrm{mM} \mathrm{NaHCO}_{3}$ treatment. FW of $S$. corniculata were decreased slightly at $100 \mathrm{mM} \mathrm{NaCl}$, but decreased markedly with increasing $\mathrm{NaCl}$ concentrations under salt stress (Fig. 1a). With increasing $\mathrm{NaHCO}_{3}$ concentrations, the FW of $S$. corniculata decreased significantly (Fig. 1b). DW of $S$. corniculata were decreased slightly by both $\mathrm{NaCl}$ and $\mathrm{NaHCO}_{3}$ stress (Fig 1). Under $300 \mathrm{mM} \mathrm{NaCl}$ and $200 \mathrm{mM} \mathrm{NaHCO}_{3}$ treatment, the stress reduced the FW of $S$. corniculata by $55.7 \%$ and $61.7 \%$, respectively, and reduced the DW of $S$. corniculata by $39.1 \%$ and $31.9 \%$, respectively. Given this evidence that, $300 \mathrm{mM} \mathrm{NaCl}$ and $200 \mathrm{mM} \mathrm{NaHCO}_{3}$ have severe shock effects on plants, $150 \mathrm{mM} \mathrm{NaCl}$ and $150 \mathrm{mM} \mathrm{NaHCO}$ were selected as the salt and alkali stress for 2-DE and metabolic analysis.

Effects of $\mathrm{NaCl}$ and $\mathrm{NaHCO}_{3}$ stress on $\mathrm{Na}^{+}, \mathrm{K}^{+}$content

The $\mathrm{Na}^{+}$contents of $S$. corniculata increased with increasing salinity and alkali levels under both $\mathrm{NaCl}$ and $\mathrm{NaHCO}_{3}$ stresses (Fig. 2). $\mathrm{K}^{+}$contents were much lower than in the controls at the lowest dose of both stresses, and decreased with increasing $\mathrm{NaCl}$ treatment intensity, but did not change obviously under $\mathrm{NaHCO}_{3}$ stress with increasing alkalinity (Fig. 2). The $\mathrm{K}^{+} / \mathrm{Na}^{+}$ratios of $S$. corniculata under $\mathrm{NaCl}$ and $\mathrm{NaHCO}_{3}$ treatment were much lower than in the controls, whereas the changes in the $\mathrm{K}^{+} / \mathrm{Na}^{+}$ratio under $\mathrm{NaCl}$ stress were much higher than under $\mathrm{NaHCO}_{3}$ stress.

\section{Comparative proteome analysis}

Four-week-old seedlings of $S$. corniculata were treated with $150 \mathrm{mM} \mathrm{NaCl}$ and $150 \mathrm{mM} \mathrm{NaHCO}_{3}$ for $72 \mathrm{~h}$. To investigate the temporal changes of protein profiles in response to $\mathrm{NaCl}$ and $\mathrm{NaHCO}_{3}$ stress, 2-DE gels from three biological replicates were analyzed to detect proteins extracted from the leaves of control and treated seedlings (Fig. 3, Supplementary Figure S1 and S2). More than 1000 protein spots were reproducibly detected on gels by the Melanie 7.0 software. The data showing significant difference between control and treatment at 0.05 level were considered up- or down-regulated protein spots. Quantitative image analysis revealed that a total of 30 protein spots changed significantly in abundance (Vol\%) by $>2.0$-fold. MALDI-TOF/TOF MS analysis of these spots was successfully performed, and the mass spectra were searched against the NCBInr database using the Mascot search engine. In total, 22 proteins were successfully identified from the 30 differentially expressed protein spots and are listed in Tables 1 and 2 (Supplementary Table S3). Among the 22 proteins, 10 proteins were observed as being differentially expressed under $\mathrm{NaCl}$ treatments and 12 proteins under $\mathrm{NaHCO}_{3}$ treatments (Fig. 3a). In addition, the expression abundance of one protein was modulated both by $\mathrm{NaCl}$ and $\mathrm{NaHCO}_{3}$ treatments, but it shows different regulation patterns under the two types of salt stress. According to KEGG pathway analysis of the protein cell function categories, the functions of these proteins could be classified into seven groups including carbohydrate metabolism, energy metabolism, photosynthesis, nucleotide metabolism, protein synthesis, stress and defense, and unknown (Fig. 4).

All of the differentially expressed proteins that responded to $\mathrm{NaCl}$ stress revealed a relatively decreased abundance in $S$. corniculata. Only a small portion of these identified proteins were induced by $\mathrm{NaHCO}_{3}$ treatments. We found that three of them, namely RuBisCO large subunit-binding protein (spot 572) and 
a

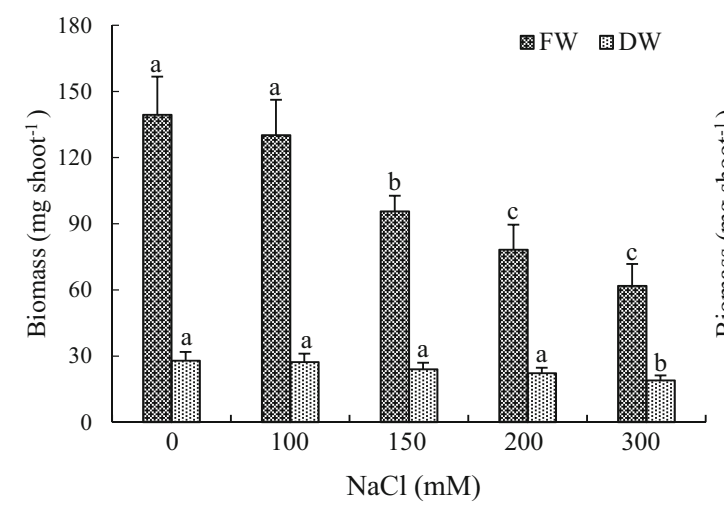

Fig. 1 Effects of $\mathrm{NaCl}$ and $\mathrm{NaHCO}_{3}$ on $S$. corniculata growth. Five-week-old seedlings were treated without stressors (control) or with $100,150,200,300 \mathrm{mM} \mathrm{NaCl}$ or $50,100,150,200 \mathrm{mM}$ $\mathrm{NaHCO}_{3}$. (a) Fresh and dry weight were measured $72 \mathrm{~h}$ after the

chloroplast RNA binding protein (spot 1008), which functions in photosynthesis, and ATP-dependent zinc metalloprotease (spot 642), which is correlated to protein processing, showed significant increases in their expression abundance.

\section{Metabolic response}

Through proteomics analysis, we have observed many differentially expressed proteins involved in various cellular metabolism pathways. To gain more insights into the modulation of metabolic processes in the $S$. corniculata response to salt and alkali stress, NMR analysis was conducted to detect the metabolic changes between the control and treated samples with $150 \mathrm{mM}$

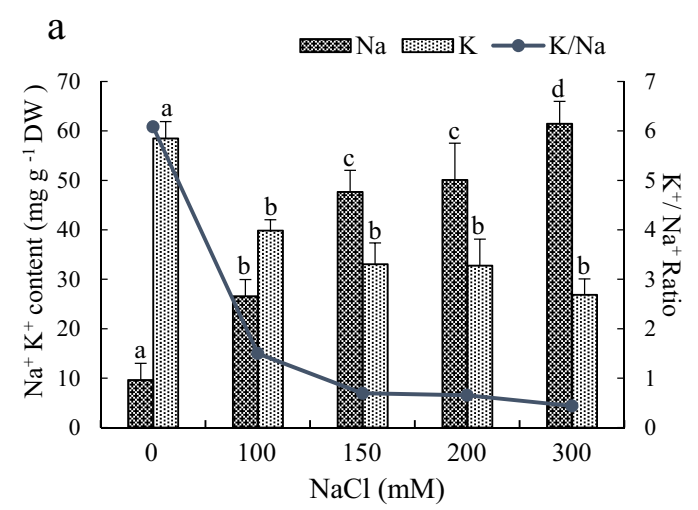

Fig. 2 Effects of (a) $\mathrm{NaCl}$ and (b) $\mathrm{NaHCO}_{3}$ stresses on $\mathrm{Na}^{+}$and $\mathrm{K}^{+}$concentrations and $\mathrm{K}^{+} / \mathrm{Na}^{+}$in $S$. corniculata. Seedlings were treated with $0,100,150,200,300 \mathrm{mM} \mathrm{NaCl}$ or $50,100,150$, b

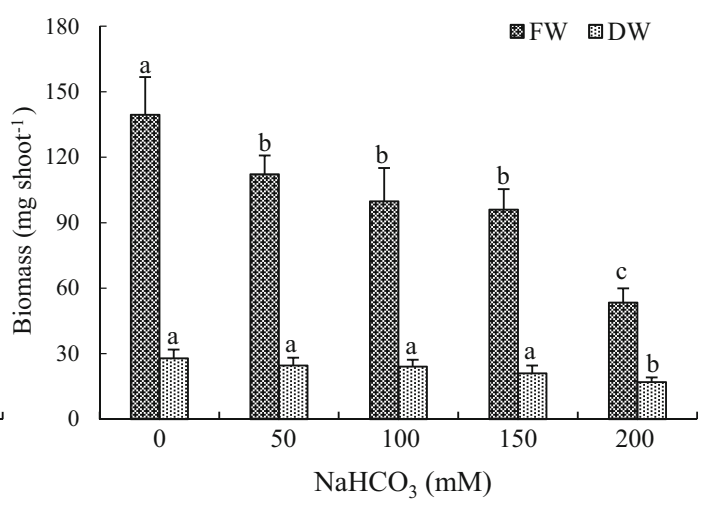

start of $\mathrm{NaCl}$ treatment. (b) Fresh and dry weight were measured $72 \mathrm{~h}$ after the start of $\mathrm{NaHCO}_{3}$ treatment. Error bars show the SE for three biological replicates. Significant differences $(p<0.05$ by one-way ANOVA analysis) are indicated by different letters

$\mathrm{NaCl}$ and $150 \mathrm{mM} \mathrm{NaHCO}$ for $72 \mathrm{~h}$. A representative ${ }^{1} \mathrm{H}$ NMR spectrum of the leaves of $S$. corniculata extracts is shown in Fig. 5 (Supplementary Figure S4). PCA results from the analysis of NMR spectral data showed alkali-exposed samples were clearly separated from control and salt-exposed samples along PC1 axis $(p<0.05)$ from the PC scores plot (Supplementary Figure S5). A total of 19 metabolites were identified in the leaves of $S$. corniculata involved in various metabolite classes, including nine amino acids (valine, glycine, alanine, leucine, isoleucine, glutamine, glutamate, aspartate and threonine), three energy storage compounds (sucrose, glucose and fructose), four intermediates in the tricarboxylic acid (TCA) cycle (malate, succinate, 2-oxoglutarate, and fumarate), one organic

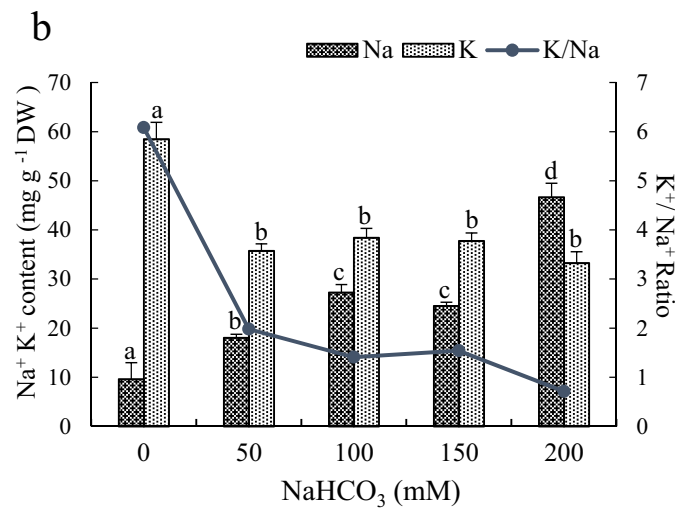

$200 \mathrm{mM} \mathrm{NaHCO}$. Error bars show the SE for three biological replicates. Significant differences $(p<0.05$ by one-way ANOVA analysis) are indicated by different letters 


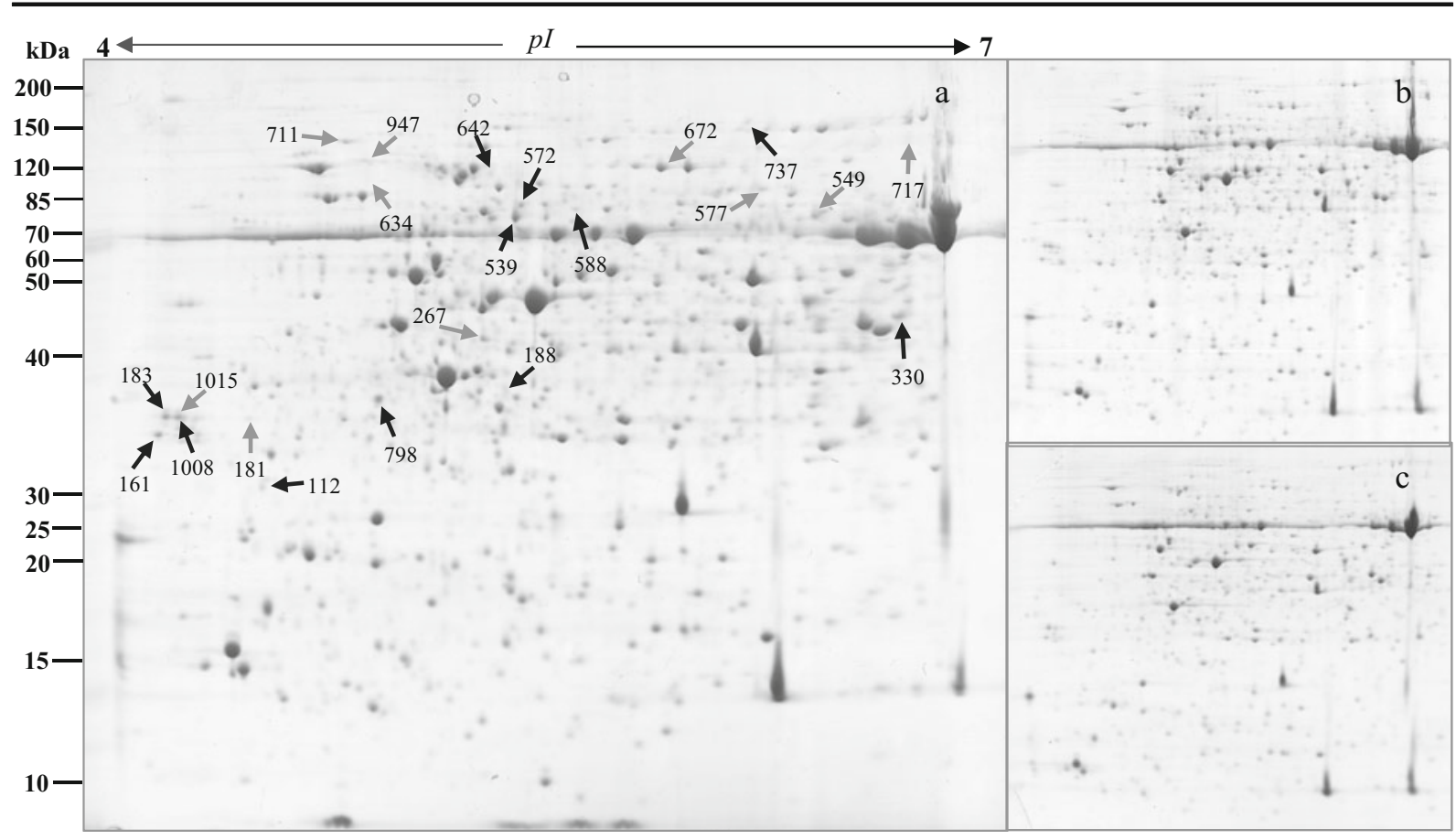

Fig. 3 Representative 2-DE gels of protein samples from $S$. corniculata under salt and alkali stresses. (a) A total of 22 statistically significant differential spots are labeled with

osmolyte (betaine) and others (dimethylamine and choline) (Fig. 6). Except sucrose and alanine, the other metabolites exhibited no significant differences under $\mathrm{NaCl}$ stress. Among the rest of these metabolites, only betaine displayed up-regulated abundance and the remaining 15 metabolites were down-regulated after $\mathrm{NaCl}$ treatment. In contrast, 11 of 19 metabolites were significantly changed under $\mathrm{NaHCO}_{3}$ stress. Almost all of these metabolites were up regulated by $\mathrm{NaHCO}_{3}$ treatment, and only one metabolite (sucrose) was downregulated. Compared with the metabolic expression of S. corniculata under $\mathrm{NaCl}$ stress, 16 of 19 metabolites (except sucrose, threonine and dimethylamine) showed significant up-regulation in $\mathrm{NaHCO}_{3}$-treated plants (Fig. 6).

\section{Discussion}

Comparing alkali stress with salt stress, the high $\mathrm{pH}$ environment that surrounds the plant root can cause the precipitation of metal ions and phosphorus, greatly affecting the absorption of inorganic anions and disrupting the ionic balance and $\mathrm{pH}$ homeostasis in plant tissues arrows. Gray and black arrows indicate salt and alkali response protein spots, respectively. (b) $\mathrm{NaCl}$ - and (c) $\mathrm{NaHCO}_{3}$ treated samples

(Shi and Zhao 1997; Yang et al. 2007, 2008c). It is understood that currently, only a few plant species of alkali-resistant halophytes can survive in saline and alkaline land (Zheng and Li 1999; Yang et al. 2008a). In our study, under $150 \mathrm{mM} \mathrm{NaHCO}_{3}$ and $\mathrm{NaCl}$ conditions, the fresh weight of $S$. corniculata declined slightly, the plants responded to alkali and salt stress by a significant inhibition of growth with increasing concentration treatment, and the phenotype changes caused by $\mathrm{NaHCO}_{3}$ stress were more obvious than the results of $\mathrm{NaCl}$ stress. These results indicated that the injurious effects of alkali stress on the growth of $S$. corniculata were more severe than for salt stress, which was consistent with previous reports (Li et al. 2009; Guo et al. 2009).

Under salt stress, $\mathrm{Na}^{+}$competes with $\mathrm{K}^{+}$for uptake into plant roots through the high affinity $\mathrm{K}^{+}$transporter and non-selective cation channels (Munns 2002; Munns and Tester 2008). The $\mathrm{Na}^{+}$contents of S. corniculata increased with increasing salinity and alkali levels under both $\mathrm{NaCl}$ and $\mathrm{NaHCO}_{3}$ stresses (Fig. 2), but $\mathrm{Na}^{+}$ accumulation in $\mathrm{NaHCO}_{3}$-treated plants was lower than in NaCl-treated plants. It is suggested that alkali stress may attributable to an inhibitory effect of high $\mathrm{pH}$ on the absorption of inorganic anions (Munns and Tester 


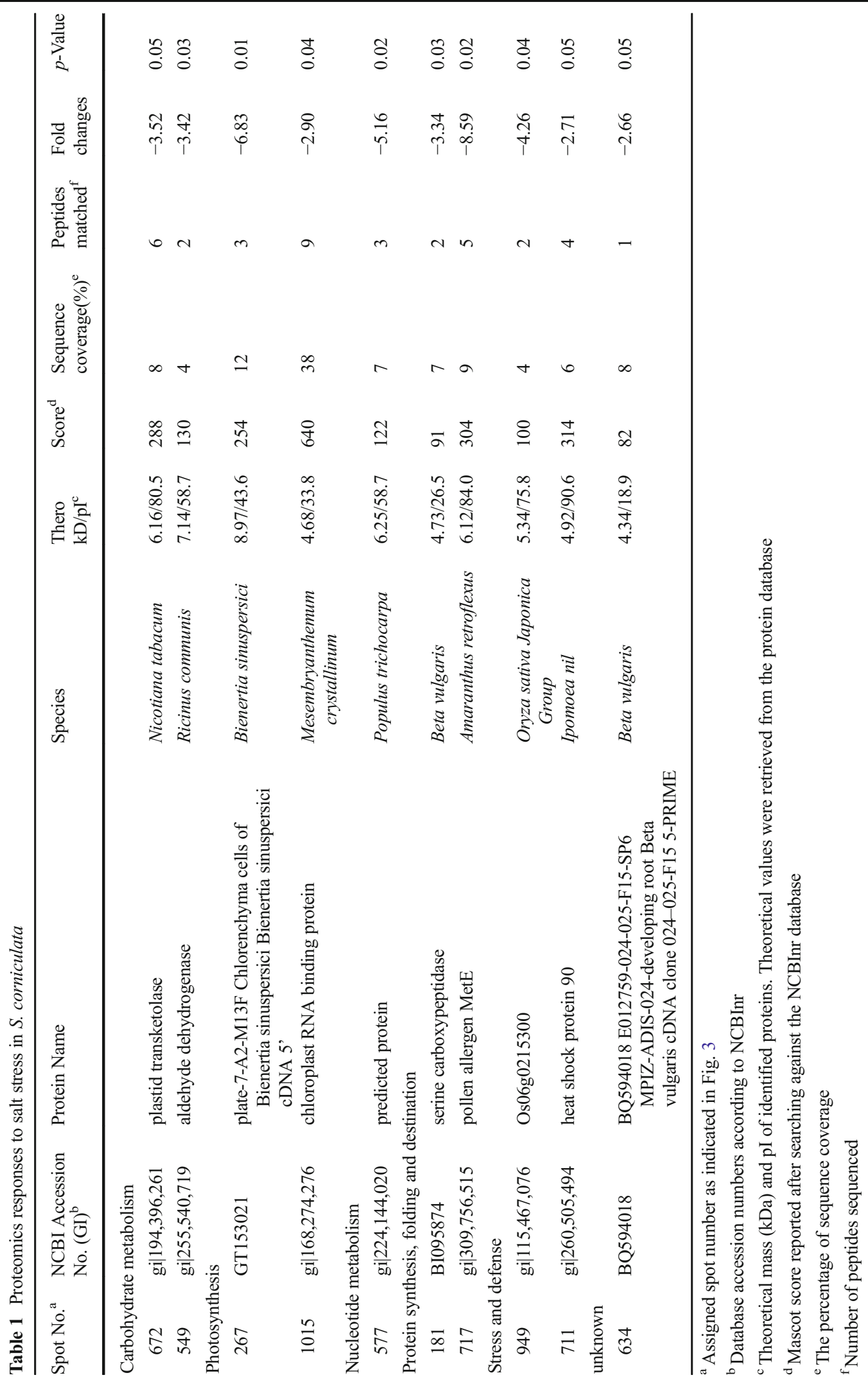




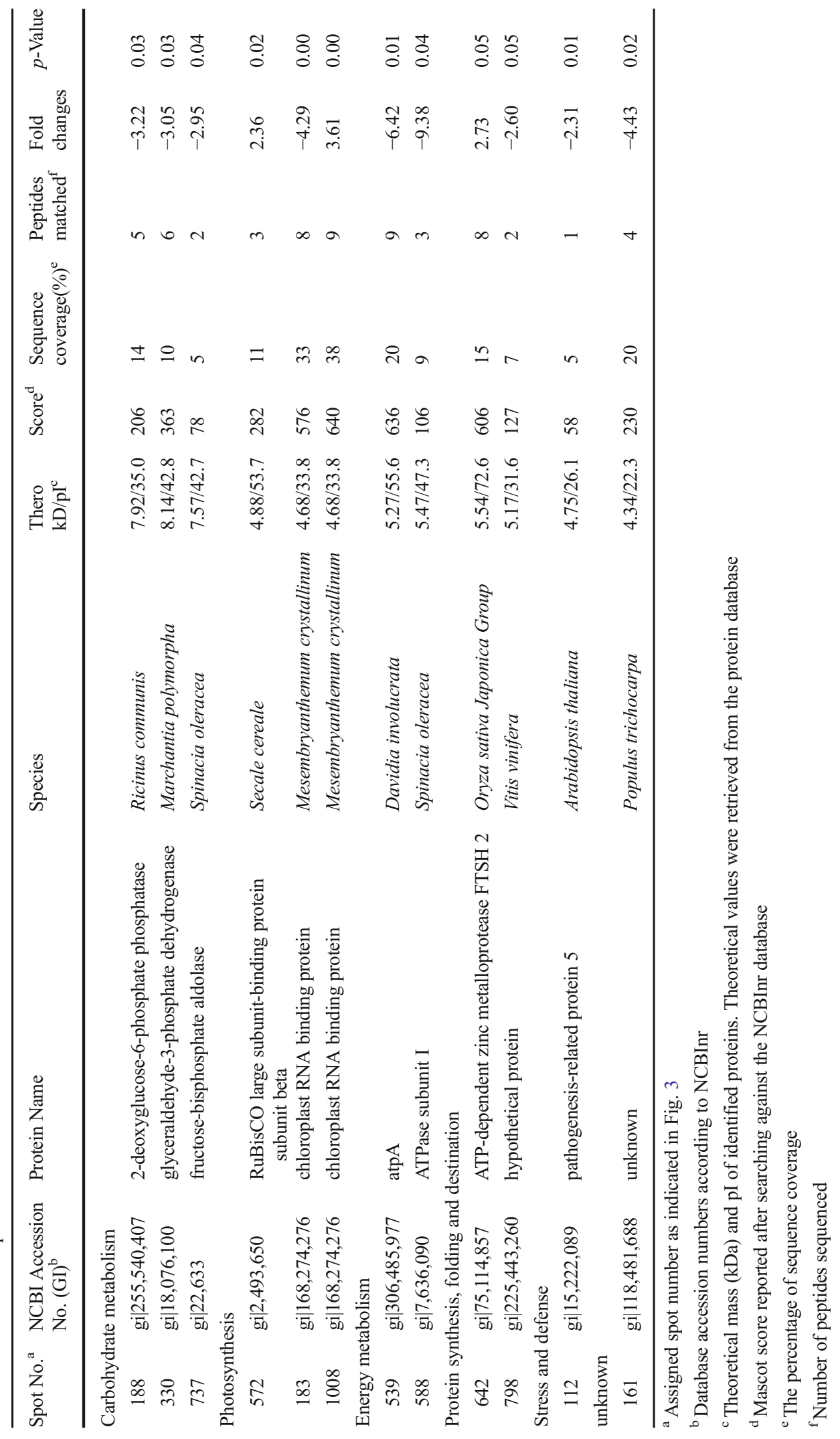




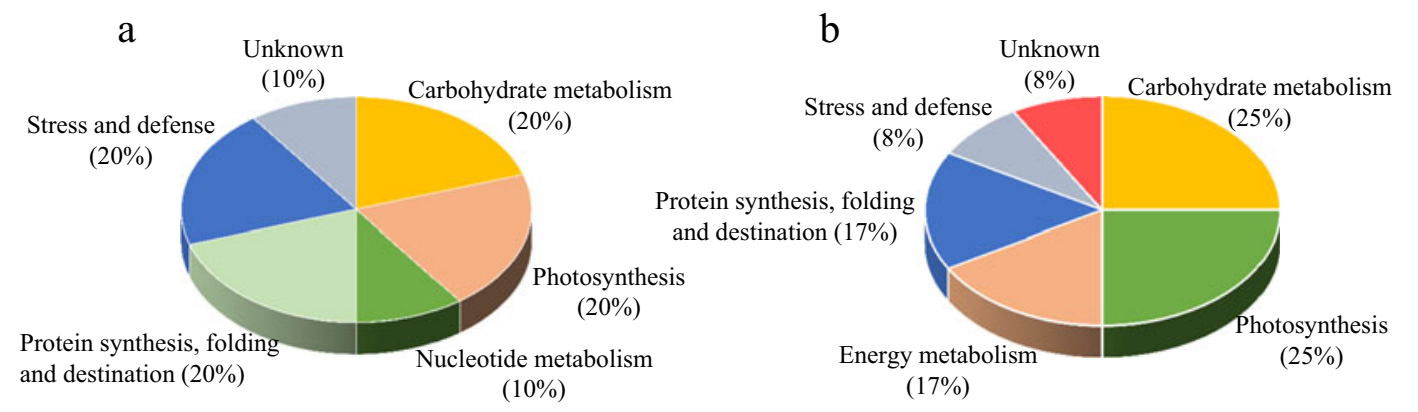

Fig. 4 Functional classification of differentially expressed proteins identified in S. corniculata under salt and alkali stresses. (a) Protein categories of seedlings under $\mathrm{NaCl}$ stress. (b) Protein categories of seedlings under $\mathrm{NaHCO}_{3}$ stress

2008). The converse situation in $\mathrm{K}^{+}$contents change mode under $\mathrm{NaCl}$ stress, it decreased with increasing $\mathrm{NaCl}$ treatment intensity. In the $\mathrm{NaHCO}_{3}$-treated plants in our study, the $\mathrm{K}^{+}$contents were clearly lower than control, but did not change significantly with increasing alkalinity (Fig. 2b). These results were consistent with the analysis of the responses of the alkali-resistant halophytes S. glauca and Puccinellia tenuiflora to salt and alkali stresses (Yang et al. 2008b; Guo et al. 2010). It should be emphasized that the $\mathrm{K}^{+}$contents did not change significantly between different level alkali stresses, which indicated that there might be no competitive inhibition between $\mathrm{Na}^{+}$and $\mathrm{K}^{+}$absorption in $S$. corniculata under alkali stress, suggesting that this plant might have a unique pathway of $\mathrm{Na}^{+}$absorption independent of the $\mathrm{K}^{+}$pathway, and that separation might be related to the resistance of alkali stress in S. corniculata.

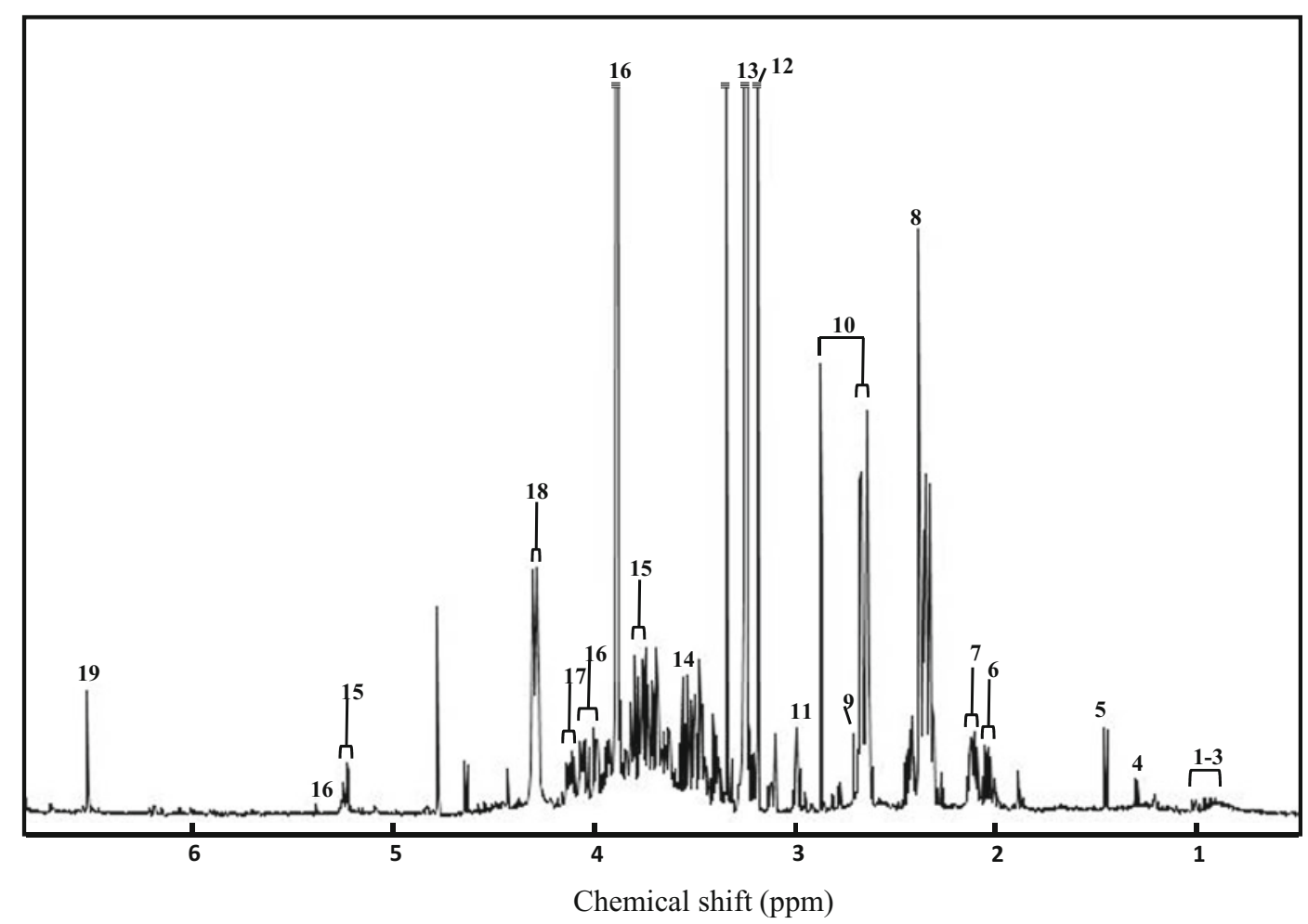

Fig. 5 A representative ${ }^{1}$ H-NMR spectrum of the metabolites identified in S. corniculata. (1) valine, (2) isoleucine, (3) leucine, (4) threonine, (5) alanine, (6) glutamate, (7) glutamine, (8) succinate, (9) dimethylamine, (10) aspartate, (11) 2-oxoglutarate, (12) choline, (13) betaine, (14) glycine, (15) glucose, (16) sucrose, (17) fructose, (18) malate, (19) fumarate 

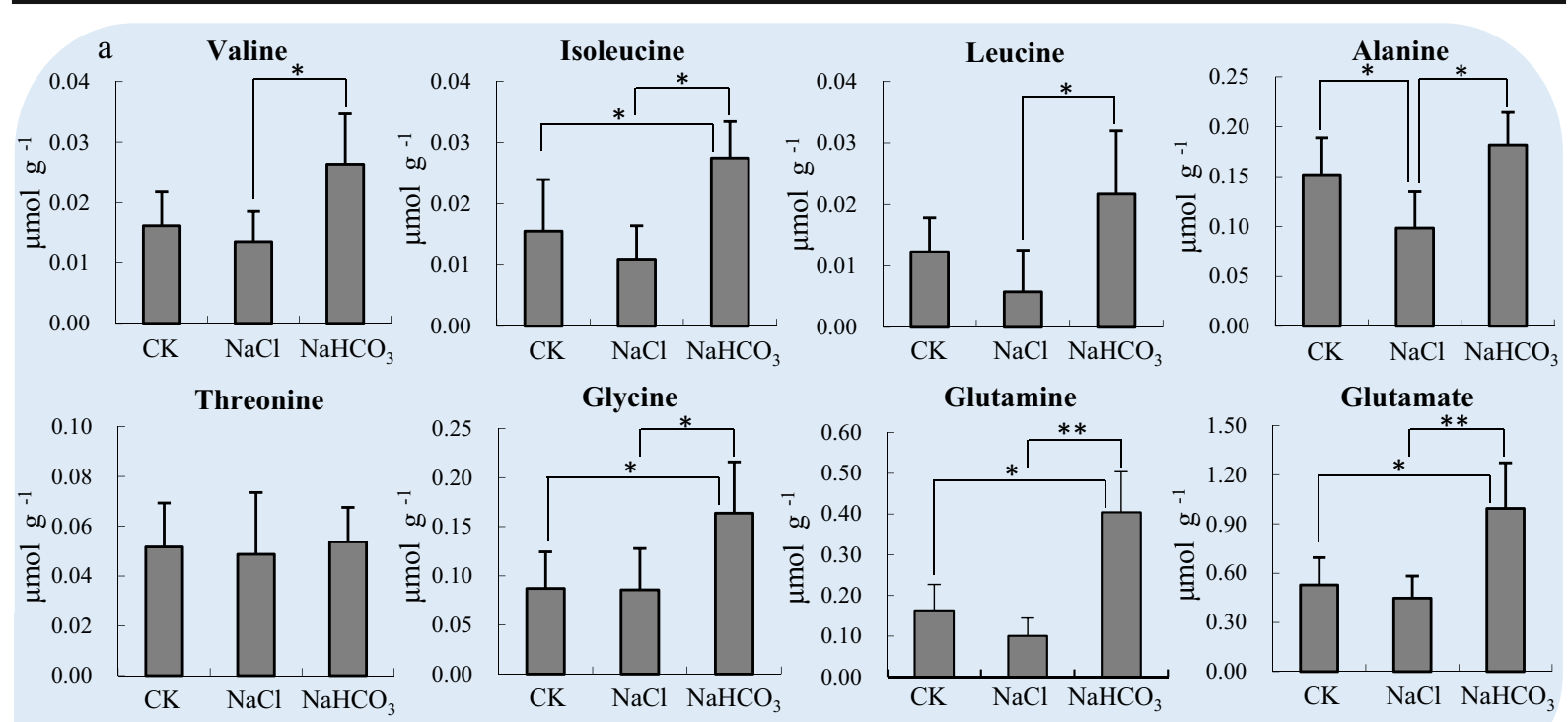

Glutamate
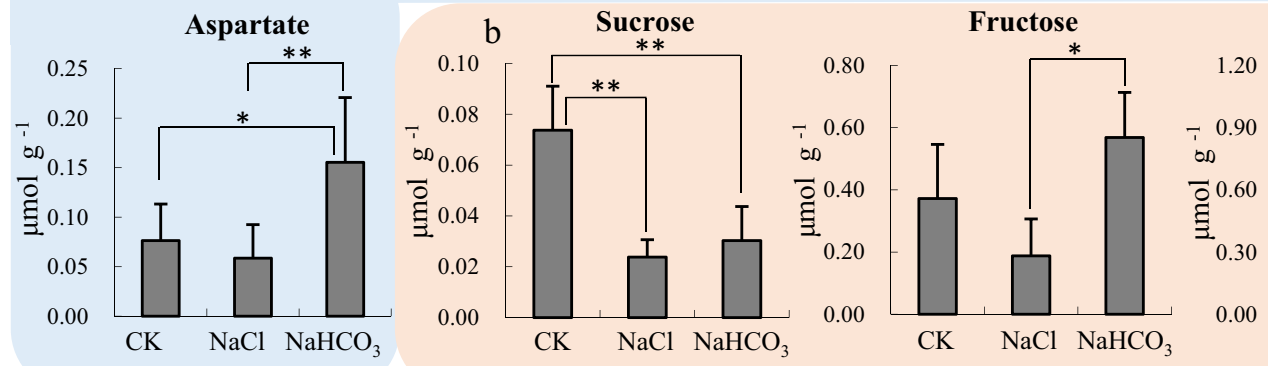

Glucose
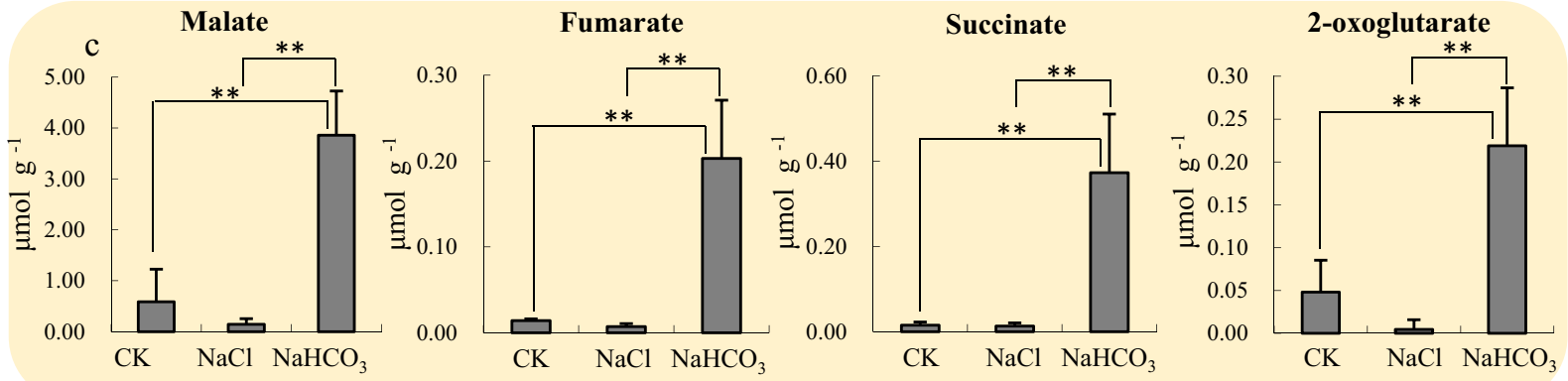

d

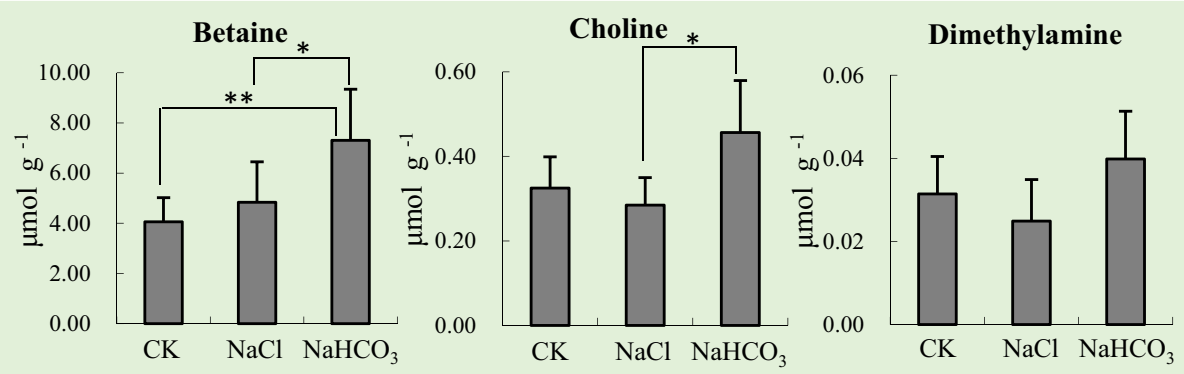

Fig. 6 Metabolomic responses to salt and alkali stresses in $S$. corniculata. (a) The response of metabolites of amino acids, (b) sugars, (c) intermediates of the TCA cycle, (d) osmolytes and others. Significant differences $(p<0.05$ and $p<0.01$ by Tukey HSD-test) are indicated by one or two asterisks 
To gain insight into the proteomic and metabolomic responses of $S$. corniculata towards alkalinity and salinity, we identified some differently expressed proteins and metabolites involved in a variety of cellular processes, mainly including carbohydrate metabolism, energy metabolism, photosynthesis, protein synthesis, stress and defense. A better understanding of these analysis data may help to determine the global responses to salt and alkali stresses in S. corniculata based on the modulation of certain key biological processes by salinity and alkalinity.

Carbohydrate metabolism

Based on our observations, two metabolizing enzymes, aldehyde dehydrogenase (spot 549) and plastid transketolase (spot 672), involved in the glycolysis and pentose phosphate pathways were down-regulated under salt stress. Transketolase catalyzes reactions in the oxidative pentose phosphate pathway and produces erythrose-4-phosphate, which is a precursor for the shikimate pathway leading to the phenylpropanoid metabolism (Henkes et al. 2001). It has previously been reported that plastid transketolase exhibits opposite expression patterns in glycophytes and halophytes under salt stress (Kim et al. 2005; Yu et al. 2011). Aldehyde dehydrogenase catalyzes the oxidation of aldehydes to their corresponding carboxylic acids and requires NAD or NADP as a co-factor (Sunkar et al. 2003). Moreover, our metabolomics data showed slight decreases in three intermediates of the tricarboxylic acid cycle (TCA cycle), 2-oxoglutarate, malate and fumarate, after salt treatment (Fig. 7). This result is consistent with the metabolic profiles of the $S$. salsa response to salinity (Wu et al. 2011). The down-regulation in these metabolites indicated that salinity induced disturbances in the TCA cycle. Taken together, these results might indicate that the carbohydrate metabolic pathways related to energy supply were inhibited by salt stress in $S$. corniculata.

We also found that two key enzymes involved in the glycolysis pathway glyceraldehyde-3-phosphate dehydrogenase (spot 330) and fructose-bisphosphate aldolase (spot 737) decreased in abundance following $\mathrm{NaHCO}_{3}$ treatment in S. corniculata. Glyceraldehyde-3phosphate dehydrogenase catalyzes the conversion of glyceraldehyde-3-phosphate to 1, 3-diphosphoglycerate. Fructose-bisphosphate aldolase is a type of lyase that catalyzes the interconversion of 1, 6-diphosphate, dihydroxyacetone phosphate and glyceraldehyde- 3-phosphate. Being in a different situation from $P$. tenuiflora, these two enzymes were all induced under alkali stress (Yu et al. 2013). Interestingly, our study demonstrates that the content of four intermediates in TCA cycle, 2-oxoglutarate, malate, fumarate and succinate were increased by more than four-fold (Fig. 7). In addition, a decrease in sucrose and increase in glucose and fructose were observed, indicating an up-regulation of the conversion of sucrose to glucose and fructose was induced by alkalinity exposure. Combined with the heightened TCA cycle activity, these results suggest that the degradation of sucrose may supply more substrate for the TCA cycle to generate extra energy, which is beneficial to $S$. corniculata under alkali stress. This result implies that the intensity of the interaction between the sugar metabolism and the TCA cycle is strengthened by alkalinity.

\section{Photosynthesis}

The primary step in energy production in the biosphere, photosynthesis, is inhibited by salt and alkali stress (Ma et al. 1997; Yang et al. 2009). Photosynthetic capacity has been observed to be much lower under both salt and alkali stresses than in control plants in the glycophytes wheat and barley, and the inhibition was more severe under alkali stress than salt stress (Yang et al. 2008c, 2009). However, the situation is different in the halophyte Chloris virgata, whose photosynthetic properties were not influenced by salt and alkali treatment below $160 \mathrm{mM}$ (Yang et al. 2008a). Our previous study analyzed the photosynthesis and chlorophyll fluorescence parameters of $S$. corniculata seedlings under different concentrations of salt or alkali stress, and the results indicated that the photosynthesis of $S$. corniculata seedlings exhibited no significant difference under low salinity stress compared with the control plants, whereas it was inhibited by high salinity and alkalinity (Wei et al. 2012). Similarly, Fv/fm, Fv'/Fm', qL, and $\varphi$ PSII were not affected by salt stress in $S$. salsa and S. aegyptiaca of the Suaeda plants (Lu et al. 2003; Askari et al. 2006).

In this work, we found two and three differentially expressed proteins related to photosynthesis in $S$. corniculata response to salt and alkali stress, respectively. Chloroplast RNA binding protein (spot 1015, spot 183 and 1008) was down-regulated by both treatments. Chloroplast RNA binding protein (cRBP) represents good candidate for mediating the function of nucleus-encoded factors which mainly regulate 


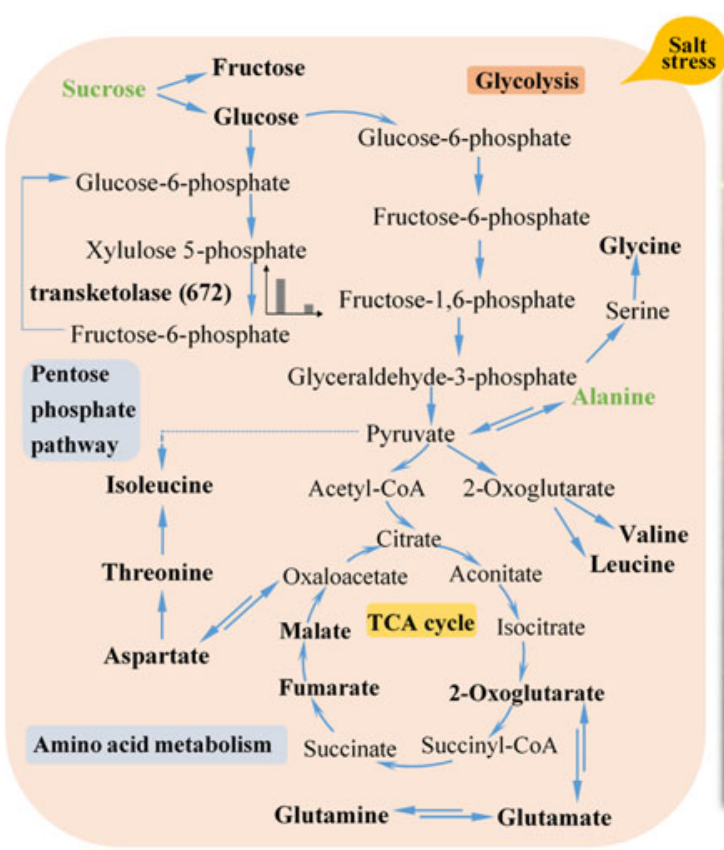

Fig. 7 Main biological pathways responses to salt and alkali stress in $S$. corniculata. The differentially expressed proteins are marked in bold, and the changes in expression abundance of each protein are plotted in a histogram. The up-regulated metabolites are

chloroplast gene expression at the posttranscriptional level (Nickelsen 2003). In the halophyte Mesembryanthemum crystallinum, cRBP was increased under salt stress at the transcript level, but it is unknown whether the protein abundance was affected (Breiteneder et al. 1994). Interestingly, we also found that the $\mathrm{RuBisCO}$ large subunit-binding protein subunit beta (spot 572) was up-regulated by alkali treatment. This protein binds non-covalently to rubisco large subunits and is implicated in the assembly of RuBisCO in higher plant chloroplasts (Musgrove and Ellis 1986). In a large-scale expressed sequence tag analysis of halophyte Tamarix hispid to examine salinity-alkali stress responses, the abundance of $\mathrm{RuBisCO}$ was significantly up-regulated under $\mathrm{NaHCO}_{3}$ stress for $52 \mathrm{~h}$ (Gao et al. 2008). Proteomics analysis of $P$. tenuiflora showed that RuBisCO was suppressed after either salt or alkali stress (Yu et al. 2011, 2013). In contrast, the RuBisCO assembling protein was induced by alkali stress in $S$. corniculata which could positively impact the expression of RuBisCO. This result is consistent with our previous findings that the leaf intercellular $\mathrm{CO}_{2}$ levels in $\mathrm{S}$. corniculata increased under $\mathrm{NaHCO}_{3}$ stress (Wei et al. 2012), which implied that this stress might enhance the $\mathrm{CO}_{2}$ fixation by $\mathrm{RuBisCO}$ and improve the

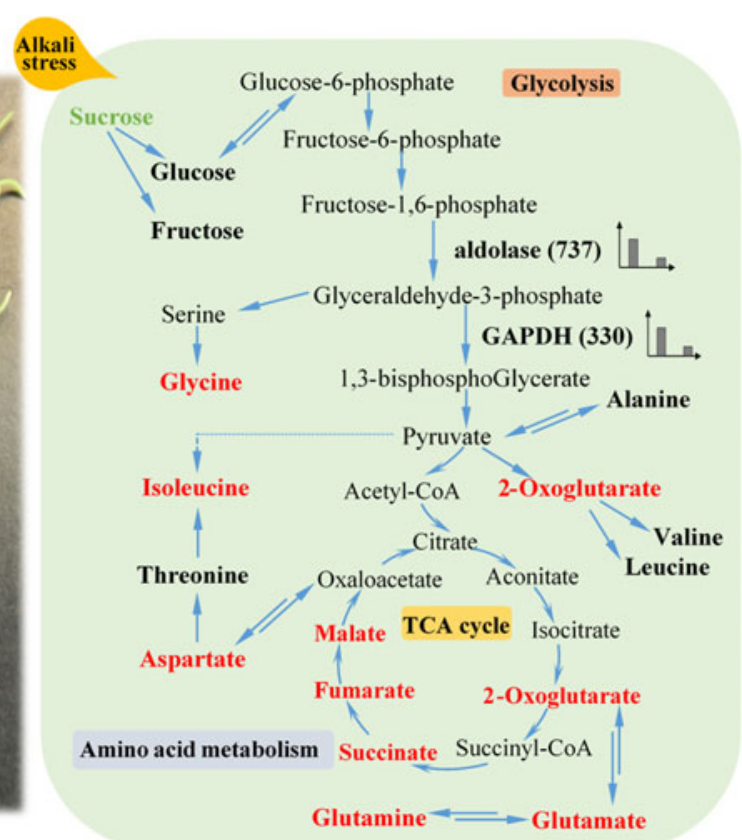

marked with bold in red and the down-regulated metabolites in green. GAPHD, glyceraldehyde 3-phosphate dehydrogenase. TCA cycle, tricarboxylic acid cycle

photosynthetic capacity. These results suggested that the modulation of photosynthesis might contribute to the ability of $S$. corniculata to cope with alkalinity.

Protein processing and amino acid metabolism

Proteomics studies revealed that the expression of many components of protein synthesis machinery are altered under salt stress conditions and suggested that protein synthesis plays a vital role in abiotic stress adaptation (Wang et al. 2008; Witzel et al. 2009; Pang et al. 2010). Our study demonstrated that serine carboxypeptidase (spot 181) and pollen allergen MetE (spot 717),respectively related to protein processing and amino acid metabolism were down-regulated under salt stress. Metabolomics analysis demonstrated that alanine which was the cross center of amino acid metabolism was decreased in $S$. corniculata with salinity exposure (Fig. 7). This results is consistent with findings in S. salsa and Thellungiella salsuginea (Lugan et al. 2010; Wu et al. 2012). These results suggest that salinity restrain amino acid metabolism in $S$. corniculata which may lead to a reduction of organic acids because it would lessen the capacity of osmotic adjustment under salt stress. 
In alkali treated plants, we observed that ATPdependent zinc metalloprotease FTSH 2 (spot 642) was more abundant in $S$. corniculata. It has been reported that FTSH is the only membrane-bound ATP-dependent protease that functions in the efficient degradation of proteins and is also involved in protection against environmental stress (Yoshioka et al. 2006). The up regulation of ATP-dependent zinc metalloprotease FTSH in our study may indicate that it can help to degrade the incorrectly folded proteins, which may be a self-protection mechanism in $S$. corniculata response to alkali stress. In support of this possibility, we also found that amino acids including glycine, isoleucine, glutamate, glutamine and aspartate were highly accumulated in S. corniculata under alkali stress (Fig. 7). The high level organic acids may compensate for the ionic imbalance induced by alkalinity and improve the osmotic adjustment through the accumulation of free amino acids for coping with alkali stress in $S$. corniculata.

Other

The accumulation of organic osmolytes, such as proline, glycine betaine, and sugar alcohols, is essential in maintaining the low intracellular osmotic potential of plants and in preventing the harmful effects of salinity stress (Verslues et al. 2006). According to our study, betaine and choline were highly accumulated in $S$. corniculata, with significant induction by alkali stress. The conversion of choline to betaine aldehyde by choline monooxygenase is a key step in the betaine biosynthesis pathway (Peel et al. 2010). The accumulation both of betaine and choline indicates the enhancement of betaine biosynthesis. In accordance with this finding, we also found that soluble sugars including fructose and glucose were more abundant in $S$. corniculata under alkali stress than in salt-treated plants. Taken together, these findings account for the positive modulation of osmotic adjustment in S. corniculata, which may be a key regulatory mechanism in $S$. corniculata to withstand alkalinity.

\section{Conclusions}

We performed integrated proteomics and metabolomics analyses to examine the different molecular mechanisms in the $S$. corniculata response to salt and alkali stress in this study. Our observations successfully identified, 22 proteins and 19 metabolites involved in several metabolic pathways. The down-regulation of certain key enzymes and intermediates demonstrates that carbohydrate metabolism, photosynthesis and the TCA cycle, all related to energy supply were inhibited by salt stress. The higher abundance of monosaccharides and intermediates of the TCA cycle accumulated in S. corniculata under alkali treatment provided more energy source for the plant to counteract the adverse effects of alkalinity. The levels of free amino acids exhibited contrasting changes in response to salt and alkali stress. Compared with salt treatment, the accumulation of organic osmolytes was much higher in alkali-treated plants. These results revealed that different regulatory mechanisms were used in the halophyte $S$. corniculata to adapt to salt and alkali stress. In particular, the up-regulation of energy metabolism and higher accumulation of organic osmolytes indicate that $S$. corniculata possess high $\mathrm{pH}$ resistance to alkali stress.

Acknowledgments This work was supported by the Fundamental Research Funds for the Central Universities (DL12CA01), the National Natural Science Foundation of China (No. 31300305), the Research Fund for the Doctoral Program of Higher Education and the Postdoctoral Funding of Heilongjiang Province.

\section{References}

Askari H, Edqvist J, Hajheidari M, Kafi M, Salekdeh GH (2006) Effects of salinity levels on proteome of Suaeda aegyptiaca leaves. Proteomics 6:2542-2554. doi:10.1002/pmic.200500328

Ayarpadikannan S, Chung E, Cho CW, So HA, Kim SO, Jeon JM, Kwak MH, Lee SW, Lee JH (2012) Exploration for the salt stress tolerance genes from a salt-treated halophyte, Suaeda asparagoides. Plant Cell Rep 31:35-48. doi:10.1007/ s00299-011-1137-4

Breiteneder H, Michalowski CB, Bohnert HJ (1994) Environmental stress-mediated differential 3 ' end formation of chloroplast RNA-binding protein transcripts. Plant Mol Biol 26:833-849

Chen YZ, Pang QY, Dai SJ, Wang Y, Chen SX, Yan XF (2011) Proteomic identification of differentially expressed proteins in Arabidopsis in response to methyl jasmonate. J Plant Physiol 168:995-1008. doi:10.1016/j.jplph.2011.01.018

Flowers TJ, Colmer TD (2008) Salinity tolerance in halophytes. New Phytol 179:945-963. doi:10.1111/j.14698137.2008.02531.x

Flowers TJ, Ward ME, Hall JL (1976) Salt tolerance in the halophyte Suaeda maritima: some properties of malate 
dehydrogenase. Phil Trans R Soc Lond B 273:523-540. doi:10.1098/rstb.1976.0029

Gao CQ, Wang YC, Liu GF, Yang CP, Jiang J, Li HY (2008) Expression profiling of salinity-alkali stress responses by large-scale expressed sequence tag analysis in Tamarix hispid. Plant Mol Biol 66:245-258. doi:10.1007/s11103-007-9266-4

Guan B, Yu JB, Lu ZH, Japhet W, Chen XB, Xie WJ (2010) Salt tolerance in two Suaeda species: seed germination and physiological responses. Asian J Plant Sci 9:194-199

Guan B, Yu JB, Wang XH, Fu YQ, Kan XY, Lin QX, Han GX, Lu ZH (2011) Physiological responses of halophyte Suaeda salsa to water table and salt stresses in coastal wetland of Yellow River Delta. Clean-Soil, Air, Water 39:1029-1035

Guo R, Shi LX, Yang YF (2009) Germination, growth, osmotic adjustment and ionic balance of wheat in response to saline and alkaline stresses. Soil Sci Plant Nutr 55:667-679. doi:10.1111/j.1747-0765.2009.00406.x

Guo QL, Shi DC, Wang DL (2010) The key physiological response to alkali stress by the alkali-resistant halophyte puccinellia tenuiflora is the accumulation of large quantities of organic acids and into the rhyzosphere. J Agron Crop Sci 196:123-135. doi:10.1111/j.1439-037X.2009.00397.x

Han N, Shao Q, Bao HY, Wang BS (2011) Cloning and characterization of a $\mathrm{Ca}^{2+} / \mathrm{H}^{+}$antiporter from halophyte Suaeda salsa L. Plant Mol Biol Rep 29:449-457. doi: 10.1007/s11105-010-0244-7

Henkes S, Sonnewald U, Badur R, Flachmann R, Stitt M (2001) A small decrease of plastid transketolase activity in antisense tobacco transformants has dramatic effects on photosynthesis and phenylpropanoid metabolism. Plant Cell 13:535-551. doi:10.1105/tpc.13.3.535

Ji CL, Wu HF, Wei L, Zhao JM, Lu HJ, Yu JB (2013) Proteomic and metabolomic analysis of earthworm Eisenia fetida exposed to different concentrations of $2,2^{\prime}, 4,4^{\prime}$ tetrabromodiphenyl ether. J Proteome 91:405-415. doi:10.1016/j.jprot.2013.08.004

Kawanabe S, Zhu TC (1991) Degeneration and conservation of Aneurolepidium chinense grassland in Northern China. J Jap Grassland Sci 37:91-99

Khan AM, Ungar IA (1998) Germination of the salt tolerant shrub Suaeda fruticosa from Pakistan: salinity and temperature responses. Seed Sci Technol 26:657-667

Kim DW, Rakwal R, Agrawal GK, Jung YH, Shibato J, Jwa NS, Iwahashi Y, Iwahashi H, Kim DH, Shim IS, Usui K (2005) A hydroponic rice seedling culture model system for investigating proteome of salt stress in rice leaf. Electrophoresis 26: 4521-4539. doi:10.1002/elps.200500334

Li XY, Liu JJ, Zhang YT, Lin JX, Mu CS (2009) Physiological responses and adaptive strategies of wheat seedlings to salt and alkali stresses. Soil Sci Plant Nutr 55:680-684. doi:10.1111/j.1747-0765.2009.00408.x

Li W, Zhang CY, Lu QT, Wen XG, Lu CM (2011) The combined effect of salt stress and heat shock on proteome profiling in Suaeda salsa. J Plant Physiol 168:1743-1752. doi:10.1016/j. jplph.2011.03.018

Liu L, Wang Y, Wang N, Dong YY, Fan XD, Liu XM, Yang J, Li HY (2011a) Cloning of a vacuolar $\mathrm{H}^{+}$-pyrophosphatase gene from the halophyte Suaeda corniculata whose heterologous overexpression improves salt, saline-alkali and drought tolerance in Arabidopsis. J Integr Plant Biol 53:731-742. doi:10.1111/j.1744-7909.2011.01066.x

Liu XL, Zhang LB, You LP, Wu HF, Zhao JM, Cong M, Li F, Wang Q, Li LZ, Li CH, Han GX, Wang GM, Xia CH, Yu JB (2011b) Metabolomic study on the halophyte Suaeda salsa in the Yellow River Delta. Clean-Soil, Air, Water 39:720-727. doi:10.1002/clen.201000515

Lu JM, Li JD (1994) The anatomical study in Suaeda Corniculata (C.A.M.) Bunge. J Northeast Norm Univ (Natural Science Edition)

Lu CM, Qiu NW, Wang BS, Zhang JH (2003) Salinity treatment shows no effects on photosystem II photochemistry, but increases the resistance of photosystem II to heat stress in halophyte Suaeda salsa. J Exp Bot 54:851-860. doi: $10.1093 /$ jxb/erg080

Lugan R, Niogret MF, Leport L, Guegan JP, Larher FR, Savoure A, Kopka J, Bouchereau A (2010) Metabolome and water homeostasis analysis of Thellungiella salsuginea suggests that dehydration tolerance is a key response to osmotic stress in this halophyte. Plant J 64:215-229. doi:10.1111/j.1365-313X.2010.04323.x

Ma HC, Fung L, Wang SS, Altman A, Hüttermann A (1997) Photosynthetic response of Populus euphratica to salt stress. Forest Ecol Manag 93:55-61. doi:10. 1016/S0378-1127(96)03943-6

Maathuis FJM, Flowers TJ, Yeo AR (1992) Sodium chloride compartmentation in leaf vacuoles of the halophyte Suaeda maritima (L.) Dum. and its relation to tonoplast permeability. J Exp Bot 43:1219-1223

Munns R (2002) Comparative physiology of salt andwater stress. Plant Cell Environ 25:239-250. doi:10.1046/j.0016-8025. 2001.00808.x

Munns R, Tester M (2008) Mechanisms of salinity tolerance. Annu. Rev Plant Biol 59:651-681. doi:10.1146/annurev. arplant.59.032607.092911

Musgrove JE, Ellis RJ (1986) The rubisco large subunit binding protein. Philos Trans R Soc B 312:419-428

Nickelsen J (2003) Chloroplast RNA-binding proteins. Curr Genet 43:392-399. doi:10.1007/s00294-003-0425-0

Pang CH, Zhang SJ, Gong ZZ, Wang BS (2005) NaCl treatment markedly enhances $\mathrm{H}_{2} \mathrm{O}_{2}$-scavenging system in leaves of halophyte Suaeda salsa. Physiol Plant 125:490-499. doi: 10.1111/j.1399-3054.2005.00585.x

Pang QY, Chen SX, Dai SJ, Chen YZ, Wang Y, Yan XF (2010) Comparative proteomics of salt tolerance in Arabidopsis thaliana and Thellungiella halophila. J Proteome Res 9: 2584-2599. doi:10.1021/pr100034f

Peel GJ, Mickelbart MV, Rhodes D (2010) Choline metabolism in glycine betaine accumulating and non-accumulating nearisogenic lines of Zea mays and Sorghum bicolor. Phytochemistry 71:404-414. doi:10.1016/j.phytochem. 2009.11.002

Qi CH, Chen M, Song J, Wang BS (2009) Increase in aquaporin activity is involved in leaf succulence of the euhalophyte Suaeda salsa, under salinity. Plant Sci 176:200-205. doi: 10.1016/j.plantsci.2008.09.019

Qiu NW, Chen M, Guo JR, Bao HY, Ma XL, Wang BS (2007) Coordinate up-regulation of $\mathrm{V}-\mathrm{H}^{+}$-ATPase and vacuolar $\mathrm{Na}^{+} / \mathrm{H}^{+}$antiporter as a response to $\mathrm{NaCl}$ treatment in a $\mathrm{C}_{3}$ halophyte Suaeda salsa. Plant Sci 172:1218-1225. doi:10.1016/j.plantsci.2007.02.013 
Shao QL, Li YJ (1998) Well Development of Suaeda salsa. Plants 3:12

Shi DC, Zhao KF (1997) Effects of $\mathrm{NaCl}$ and $\mathrm{Na}_{2} \mathrm{CO}_{3}$ on growth of Puccinellia tenuiflora and on present state of mineral elements in nutrient solution. Acta Pratacu Sin 6:51-61

Song J, Feng G, Tian C, Zhang FS (2006) Osmotic adjustment traits of Suaeda physophora, Haloxylon ammodendron and Haloxylon persicum in field or controlled conditions. Plant Sci 170:113-119. doi:10.1016/j.plantsci.2005.08.004

Song J, Chen FG, Jia YH, Wang BS, Zhang FS (2009) Effect of salinity on growth, ion accumulation and the roles of ions in osmotic adjustment of two populations of Suaeda salsa. Plant Soil 314:133-141. doi:10.1007/s11104-008-9712-3

Sunkar R, Bartels D, Kirch HH (2003) Overexpression of a stressinducible aldehyde dehydrogenase gene from Arabidopsis thaliana in transgenic plants improves stress tolerance. Plant J 35:452-464. doi:10.1046/j.1365-313X.2003.01819.x

Verslues PE, Agarwal M, Katiyar-Agarwal S, Zhu JH, Zhu JK (2006) Methods and concepts in quantifying resistance to drought, salt and freezing, abiotic stresses that affect plant water status. Plant J 45:523-539. doi:10.1111/j.1365-313X. 2005.02593.x

Wallender WW, Tanji KK (1990) Agricultural salinity assessment and management. Am Soc Civ Eng. New York pp:1-112. ISBN: 978-0-7844-1169-8

Wang BS, Lüttge U, Ratajczak R (2001) Effects of salt treatment and osmotic stress on V-ATPase and V-PPase in leaves of the halophyte Suaeda salsa. J Exp Bot 52:2355-2365. doi: $10.1093 /$ jexbot $/ 52.365 .2355$

Wang BS, Lüttge U, Ratajczak R (2004) Specific regulation of SOD isoforms by $\mathrm{NaCl}$ and osmotic stress in leaves of the $\mathrm{C}_{3}$ halophyte Suaeda salsa L. J Plant Physiol 161:285-293. doi: 10.1078/0176-1617-01123

Wang XQ, Yang PF, Gao Q, Liu XL, Kuang TY, Shen SH, He YK (2008) Proteomic analysis of the response to high-salinity stress in Physcomitrella patens. Planta 228:167-177. doi:10.1007/s00425-008-0727-Z

Wei L, Pang QY, Zhang AQ, Guo J, Yan XF (2012) Effects of salt and alkali stresses on photosynthetic characteristics of Suaeda corniculata seedlings. J Northeast For Univ 40:32-35

Wetson AM, Flowers TJ (2010) The effect of saline hypoxia on growth and ion uptake in Suaeda maritima. Funct Plant Biol 37:646-655. doi:10.1071/FP09270

Witzel K, Weidner A, Surabhi GK, Borner A, Mock HP (2009) Salt stress-induced alterations in the root proteome of barley genotypes with contrasting response towards salinity. J Exp Bot 60:3545-3557. doi:10.1093/jxb/erp198

Wu HF, Liu XL, You LP, Zhang LB, Yu JB, Zhou D, Zhao JM, Feng JH (2011) Salinity-induced effects in the halophyte Suaeda salsa using NMR-based metabolomics. Plant Mol Biol Rep 30:590-598. doi:10.1007/s11105-011-0368-4

Wu HF, Liu XL, You LP, Zhang LB, Zhou D, Feng JH, Zhao JM, Yu JB (2012) Effects of salinity on metabolic profiles, gene expressions, and antioxidant enzymes in halophyte Suaeda salsa. J Plant Growth Regul 31:332-341. doi:10.1007/ s00344-011-9244-6
Wu HF, Liu XL, Zhang XY, Ji CL, Zhao JM, Yu JB (2013) Proteomic and metabolomic responses of clam Ruditapes philippinarum to arsenic exposure under different salinities. Aquat Toxicol 136-137:91-100. doi: 10.1016/j.aquatox.2013.03.020

$\mathrm{Xu}$ L (2004) Methods of chemometrics. Science Press, Beijing, pp. 221-227

Yang CW, Chong JN, Li CY, Kim C, Shi DC, Wang DL (2007) Osmotic adjustment and ion balance traits of an alkali resistant halophyte Kochia sieversiana during adaptation to salt and alkali conditions. Plant Soil 294:263-276. doi:10.1007/s11104-007-9251-3

Yang CW, Jianaer A, Li CY, Shi DC, Wang DL (2008a) Comparison of the effects of salt-stress and alkali-stress on photosynthesis and energy storage of an alkali-resistant halophyte Chloris virgata. Photosynthetica 46:273-278

Yang CW, Shi DC, Wang DL (2008b) Comparative effects of salt stress and alkali stress on growth, osmotic adjustment and ionic balance of an alkali resistant halophyte Suaeda glauca (Bge). Plant Growth Regul 56:179-190. doi:10.1007/s10725-008-9299-y

Yang CW, Wang P, Li CY, Shi DC, Wang DL (2008c) Comparison of effects of salt and alkali stresses on the growth and photosynthesis of wheat. Photosynthetica 46:107-114

Yang CW, Xu HH, Wang LL, Liu J, Shi DC, Wang DL (2009) Comparative effects of salt-stress and alkali-stress on the growth, photosynthesis, solute accumulation, and ion balance of barley plants. Photosynthetica 47:79-86

Yoshioka M, Uchida S, Mori H, Komayama K, Ohira S, Morita N, Nakanishi T, Yamamoto Y (2006) Quality control of photosystem II. Cleavage of reaction center D1 protein in spinach thylakoids by $\mathrm{FtsH}$ protease under moderate heat stress. J Biol Chem 281:21660-21669. doi:10.1074/jbc.M602896200

Yu JJ, Chen SX, Zhao Q, Wang T, Yang CP, Diaz C, Sun GR, Dai SJ (2011) Physiological and proteomic analysis of salinity tolerance in Puccinellia tenuiflora. J Proteome Res 10:38523870. doi:10.1021/pr101102p

Yu JJ, Chen SX, Wang T, Sun GR, Dai SJ (2013) Comparative Proteomic Analysis of Puccinellia tenuiflora Leaves under $\mathrm{Na}_{2} \mathrm{CO}_{3}$ Stress. Int J Mol Sci 14:1740-1762. doi:10.3390/ijms 14011740

Zhang HY, Zhao KF (1998) Effects of salt and water stresses on osmotic adjustment of Suaeda salsa seedlings. Acta Bot Sin 40:56-61

Zhang L, Ma XL, Zhang Q, Ma CL, Wang PP, Sun YF, Zhao YX, Zhang H (2001) Expressed sequence tags from a NaCltreated Suaeda salsa cDNA library. Gene 267:193-200. doi:10.1016/S0378-1119(01)00403-6

Zheng HY, Li JD (1999) Form and dynamic trait of halophyte community. In: Zheng HY (ed) Saline Plants in Songnen Plain and Restoration of Alkaline-Saline Grass. Science Press, Beijing, pp. 137-138

Zhu JK (2001) Plant salt tolerance. Trends Plant Sci 6:66-71. doi: 10.1016/S1360-1385(00)01838-0 